\title{
Research on the maximum fire smoke temperature beneath tunnel ceilings using longitudinal ventilation
}

\author{
Hui Yang ${ }^{1, *}$, Bingyan Dong ${ }^{1}$, Sijian Zhang ${ }^{2}$, Dahui Sun $^{3}$ and Kirill Lushin ${ }^{4}$ \\ ${ }^{1}$ Beijing University of Civil Engineering and Architecture, Beijing Key Laboratory of Heating, Gas \\ Supply, Ventilating and Air Conditioning Engineering, 100044 Beijing, PR China \\ ${ }^{2}$ China Architecture Design \& Research Group, 100044 Beijing, PR China \\ ${ }^{3}$ Beijing Institute of Architectural Design Group, 100044 Beijing, PR China \\ ${ }^{4}$ Moscow State University of Civil Engineering, Yaroslavskoe shosse, 26, Moscow, 129337, Russia
}

\begin{abstract}
The maximum fire smoke temperature beneath tunnel ceilings using longitudinal ventilation was studied by both small-scale experiments and numerical simulations for a small heat release rate (HRR) fire. And then, the accuracy of the numerical simulation is verified. A numerical simulation is subsequently employed to modify the Kurioka model for cases in large HRR. Then, the modified Kurioka model is verified by various on-site high HRR fire experimental results conducted by other authors.
\end{abstract}

\begin{tabular}{|c|c|c|c|}
\hline \multicolumn{3}{|c|}{ Nomenclature } & \\
\hline$\Delta \mathrm{T}_{\max }$ & $\begin{array}{c}\text { Maximum excess temperature of } \\
\text { gas layer at downstream region }(\mathrm{K})\end{array}$ & $\mathrm{H}_{\mathrm{d}}$ & $\begin{array}{c}\text { Height from the surface of fire source to } \\
\text { tunnel ceiling }(\mathrm{m})\end{array}$ \\
\hline $\mathrm{T}_{0}$ & Ambient temperature $(\mathrm{K})$ & $\mathrm{g}$ & The gravitational acceleration $\left(\mathrm{m} \cdot \mathrm{s}^{-2}\right)$ \\
\hline $\mathrm{Q}^{*}$ & Dimensionless heat release rate & $\mathrm{u}$ & Ventilation velocity $\left(\mathrm{m} \cdot \mathrm{s}^{-1}\right)$ \\
\hline $\mathrm{Fr}$ & Froude number & $\mathrm{L}$ & Similarity ratio \\
\hline $\mathrm{Q}$ & Heat release rate $(\mathrm{kW})$ & $\mathrm{q}$ & Low heat value of methane $\left(\mathrm{MJ} \cdot \mathrm{m}^{-3}\right)$ \\
\hline$\rho_{0}$ & Ambient air density $\left(\mathrm{kg} \cdot \mathrm{m}^{-3}\right)$ & $\mathrm{V}$ & Flow rate of methane $\left(\mathrm{m}^{3} \cdot \mathrm{s}^{-1}\right)$ \\
\hline $\mathrm{C}_{\mathrm{p}}$ & $\begin{array}{c}\text { Specific heat at constant pressure } \\
\left(\mathrm{kJ} \cdot \mathrm{kg}^{-1} \cdot \mathrm{K}^{-1}\right)\end{array}$ & $\mathrm{T}_{\max }$ & The Maximum fire smoke temperature $(\mathrm{K})$ \\
\hline
\end{tabular}

\section{Introduction}

When the tunnel fires, the high temperature smoke can not only bring serious threat to people's lives ${ }^{[1-3]}$, but also cause serious thermal damage to tunnel structure, and even collapsed $^{[4]}$. Accurately predicting the maximum fire smoke temperature beneath the tunnel ceiling is meaningful.

\footnotetext{
* Corresponding author: yanghui@bucea.edu.cn
} 
The maximum fire smoke temperature beneath tunnel ceilings has been studied by researchers using both experimental and numerical methods. Ying Zhen Li et al. [5] analyzed the effects of different ventilation systems, ventilation velocities, HRRs, tunnel geometries and fire sources on the maximum excess fire smoke temperature beneath the ceiling in large tunnel fire tests. Ying Zhen Li et al. [6] conducted model-scale experiments to investigate the maximum excess fire smoke temperature beneath the tunnel ceiling. L.H. $\mathrm{Hu}$ et al. [7] experimentally and numerically studied the maximum fire smoke temperature under the tunnel ceiling. The comparison between value predicted by CFD and the value obtained from experiments showed that good agreement was achieved. In 2003, Kurioka, Oka et al. [8] proposed a model to predict the maximum smoke temperature under the tunnel ceiling based on model scale experiments, as shown in Eq. 1. Other authors demonstrated the accuracy of the Kurioka model using experimental or numerical methods. ${ }^{\text {[ }}$ 7,9]

$$
\frac{\Delta \mathrm{T}_{\max }}{T_{0}}=\gamma\left(\frac{Q^{* 2 / 3}}{F r^{1 / 3}}\right)^{\varepsilon},\left\{\begin{array}{l}
\gamma=1.77, \varepsilon=\frac{6}{5}, \frac{Q^{* 2 / 3}}{F r}<1.35 \\
\gamma=2.54, \varepsilon=0, \frac{Q^{* 2 / 3}}{F r} \geq 1.35 \\
Q^{*}=Q /\left(\rho_{0} C_{p} T_{0} g^{1 / 2} H_{d}^{5 / 2}\right) \\
F r=\frac{u^{2}}{g H_{d}}
\end{array}\right.
$$

Obviously, the Kurioka model indicates that the maximum excess temperature of the fire smoke layer at the downstream region remains constant for cases in which $\frac{Q^{* 2 / 3}}{\mathrm{Fr}^{1 / 3}}$ is larger than 1.35. It means that for low HRR fires, the maximum fire smoke temperature is proportional to the four fifth power of the HRR until the HRR reaches a certain value. After that value, the maximum fire smoke temperature beneath the tunnel ceiling would be independent of HRR.

However, other published research work is not consistent with the Kurioka model, particularly when HRR is great. According to the studies of Anders Lonnermark, Haukur Ingason, et al. [10-12], the maximum fire smoke temperature beneath a tunnel ceiling measured by Anders Lonnermark et al. in 2003 in Runehamar tunnel experiments has great difference with those temperatures predicted by the Kurioka model. The comparison of the results indicates that the Kurioka model fails to predict the maximum fire smoke temperature beneath the tunnel ceiling with large HRR values. Wang Jun et al. [13] found that there exists some defect of the predicted values by the existing model deviates from the experimental data with the cases without tunnel ventilation or with very small ventilation velocities.

The present study conducted model-scale experiments to prove the validity of the numerical simulation, which was subsequently used to simulate fire scenarios with large HRR values. In terms of simulation results, the present study modified the Kurioka model for predicting the maximum fire smoke temperature beneath the tunnel ceiling for cases of large HRR. The accuracy of modified Kurioka model formulas was validated by the existing experimental data. 


\section{Experimental procedure}

\subsection{Experimental methods}

\subsubsection{Model tunnel}

A $1 / 20$ scale tunnel with a rectangular cross-sectional shape was employed in the experiments. The ventilation method of the tunnel is longitudinal. The dimensions of the tunnel are $0.4 \mathrm{~m} \times 0.4 \mathrm{~m} \times 8 \mathrm{~m}$, as shown in Fig. 1. The tunnel was made of stainless steel. To measure the longitudinal ventilation velocity inside the tunnel, a hot wire anemometer was used at the position $1.5 \mathrm{~m}$ and $3 \mathrm{~m}$ from the plenum chamber as shown in Fig. 2. A motor and valve frequency converter adjusted the air flow rate inside the tunnel. The temperature was measured by a K-type thermocouple made of nickel chromium-nickel silicon. The external diameter of the thermocouple was $1 \mathrm{~mm}$, and the upper temperature limit of the thermocouple was $800^{\circ} \mathrm{C} .24$ thermocouples in total were placed by the medial axis of tunnel, as shown in Fig. 2. The thermocouples were previously calibrated.

Two velocity measuring holes are arranged at the top of the test section $1.5 \mathrm{~m}$ and $3 \mathrm{~m}$ away from the plenum chamber respectively. Four velocity measuring points are selected at each measuring hole. The ventilation velocity of the cross section of the velocity measuring hole is measured and the longitudinal wind velocity is obtained by taking the average value of these velocities.

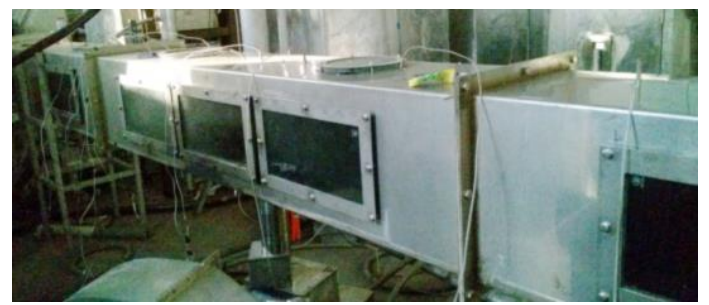

Fig. 1. Photo of $1 / 20$ model-scale tunnel

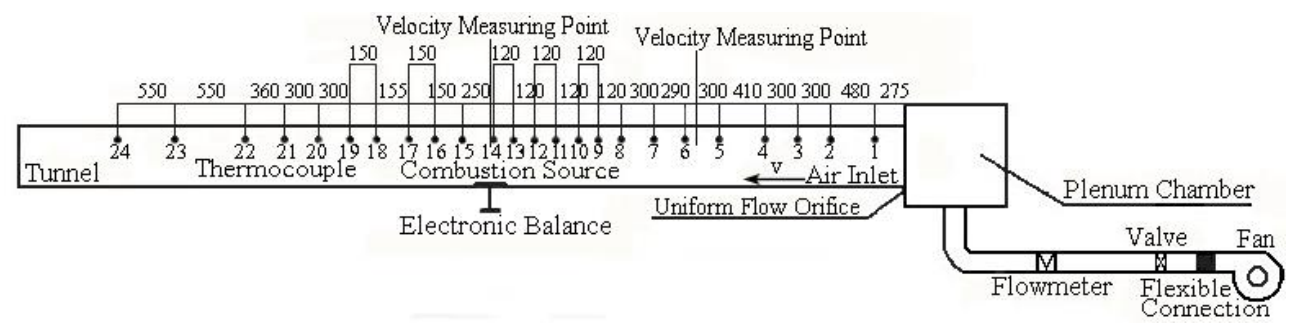

Fig. 2. Schematic diagram of tunnel and thermocouple distribution (unit: $\mathrm{mm}$ )

\subsubsection{Experimental conditions}

Experiments with model in scale of $1 / 20$ were conducted in a laboratory. Buoyancy rules air flow in a tunnel so that the Froude similarity criteria is considered in the experiments [11-12]. The correlation for Temperature、Velocity and Heat Release Rate in the large scale and model scale is $T_{m} / T_{r}=1 、 v_{m} / v_{r}=L^{1 / 2}$ and $Q_{m} / Q_{r}=L^{5 / 2}$ respectively $^{[14-15]}$. Where, $L$ is the length; $m$ represents model scale; $r$ represents large scale.

Gasoline was adopted to simulate the fire source in the experiments. The fuel tray is 4.5 
$\mathrm{cm}$ tall, with the diameter of $12.6 \mathrm{~cm}$, and it is located $3 \mathrm{~m}$ from the plenum chamber. The heat release rate is determined by the mass loss rate method ${ }^{[16]}$. The burning rate was obtained by electronic balance monitoring of the mass loss of the fuel. The monitoring time interval of the electronic balance was $1 \mathrm{~min}$, and the electronic balance was previously calibrated.

velocities were tested in the experiments, the values are $0.1 \mathrm{~m} \cdot \mathrm{s}^{-1} 、 0.13 \mathrm{~m} \cdot \mathrm{s}^{-1} 、 0.15 \mathrm{~m} \cdot \mathrm{s}^{-1}$ 、 $0.19 \mathrm{~m} \cdot \mathrm{s}^{-1} 、 0.22 \mathrm{~m} \cdot \mathrm{s}^{-1} 、 0.25 \mathrm{~m} \cdot \mathrm{s}^{-1} 、 0.33 \mathrm{~m} \cdot \mathrm{s}^{-1} 、 0.35 \mathrm{~m} \cdot \mathrm{s}^{-1} 、 0.39 \mathrm{~m} \cdot \mathrm{s}^{-1} 、 0.46 \mathrm{~m} \cdot \mathrm{s}^{-1} 、 0.57 \mathrm{~m} \cdot \mathrm{s}^{-1} 、$ $0.7 \mathrm{~m} \cdot \mathrm{s}^{-1} 、 0.85 \mathrm{~m} \cdot \mathrm{s}^{-1} 、 0.87 \mathrm{~m} \cdot \mathrm{s}^{-1}$ respectively. And mass of combusted fuel in each case is $180 \mathrm{~g}$. HRR varied with different ventilation velocity in the experiments.

\subsection{Numerical simulation conditions}

To verify the validity of the numerical simulation, numerical simulation was adopted to obtain the maximum fire smoke temperature beneath the tunnel ceiling in the experiments, and the simulation result and experimental result were then compared.

\subsubsection{Numerical simulation model}

On the basis of a model-scale tunnel, the model used in the numerical simulation was appropriately simplified to reduce computational time. The dimensions of the simplified model were $0.4 \mathrm{~m} \times 0.4 \mathrm{~m} \times 8 \mathrm{~m}$. The radius of the fire source inside the tunnel was 0.063 $\mathrm{m}$, and the source was located at the geometrical center of the tunnel floor. The entire tunnel was considered the computational domain, which was divided into 1,490,000 hexahedron elements.

\subsubsection{Numerical simulation conditions}

The present study used the standard $k-\varepsilon$ turbulence model including the buoyancy modification. To simplify the combustion process, methane was the fire source in the numerical simulation instead of gasoline. The combustion was considered a stoichiometric reaction of methane and air, which can be defined as:

$$
\mathrm{CH}_{4}+2 \mathrm{O}_{2}=\mathrm{CO}_{2}+2 \mathrm{H}_{2} \mathrm{O}
$$

The eddy dissipation model (EDM) is employed to define the combustion reaction. EDM is based on the assumption that the chemical reaction is fast relative to the flow transport processes. The products are assumed to form instantaneously as the reactants mix at the molecular level. Therefore, the reaction rate depends directly on the reactant mixing time ${ }^{[17]}$.

The inlet velocity of methane was developed by the heat value of methane and the HRR measured in the experiments to ensure that the HRR in the experiments was equal to the HRR in the numerical simulation, as shown in Eq. (3):

$$
Q=q V
$$

Where $q$ represents the heat value of methane $\left(35.9 \times 10^{3} \mathrm{~kJ} \cdot \mathrm{m}^{-3}\right) ; Q$ represents HRR; $V$ represents the flow rate of methane. Inflow air temperature in each case was equal to the ambient temperature in the experiments. The velocity inlet boundary was used for the methane-inlet surface and the air-inlet surface. The opening boundary was used for the gas-outlet surfaces. The tunnel envelope structure was simplified to the adiabatic solid wall, as shown in Fig. 3. All solid boundaries were assumed to be no-slip. The ventilation method of the tunnel in the numerical simulation is longitudinal. The numerical simulation 
employed the SIMPLE method. The simulation solver was CFX 15.0. The simulation case is the same as the experimental case.

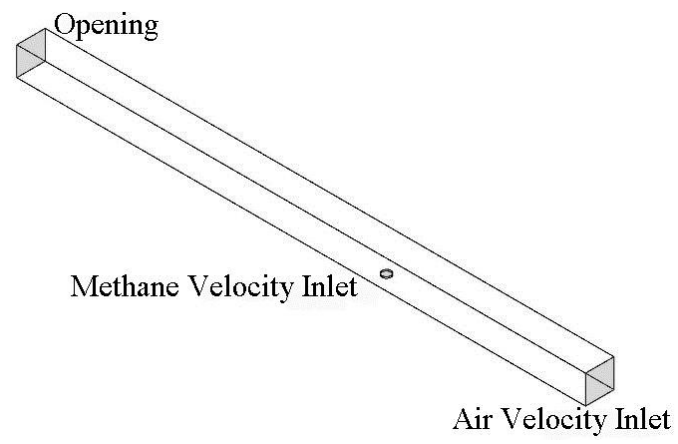

Fig. 3. Boundary conditions of numerical simulation

\subsection{Results}

The following is a summary of the simulation results compared with experimental results, and the predicted value of the maximum fire smoke temperature beneath tunnel ceiling is presented, as shown in Table 1. $Q^{*}$ and $F r$ were determined by Eq. (1), and the value of $T_{0}$ was equal to the actual ambient temperature during the experiments. The comparison of the different methods for obtaining the maximum fire smoke temperature beneath the tunnel ceiling is shown in Fig. 4.

Table 1. Comparison of maximum fire smoke temperature obtained by three different methods

\begin{tabular}{|c|c|c|c|c|c|c|c|c|}
\hline \multirow[b]{2}{*}{ No. } & \multirow[b]{2}{*}{$\begin{array}{l}\text { HRR } \\
(\mathrm{kW})\end{array}$} & \multirow[b]{2}{*}{$\begin{array}{c}\mathrm{u} \\
\left(\mathrm{m} \cdot \mathrm{s}^{-1}\right)\end{array}$} & \multirow[b]{2}{*}{$\begin{array}{c}\mathrm{T}_{0} \\
\left({ }^{\circ} \mathrm{C}\right)\end{array}$} & \multirow[b]{2}{*}{$\frac{Q^{* 2 / 3}}{F r^{1 / 3}}$} & \multicolumn{3}{|c|}{$\mathrm{T}_{\max }\left({ }^{\circ} \mathrm{C}\right)$} & \multirow{2}{*}{$\begin{array}{l}\text { Deviation of } \\
\text { Simulation } \\
\text { Value and } \\
\text { Experimental } \\
\text { Value }(\%)\end{array}$} \\
\hline & & & & & $\begin{array}{l}\text { Simulation } \\
\text { Value }\end{array}$ & $\begin{array}{c}\text { Experimental } \\
\text { Value }\end{array}$ & $\begin{array}{l}\text { Predicted } \\
\text { Value }\end{array}$ & \\
\hline $\begin{array}{c}\text { Case } \\
1\end{array}$ & 5.522 & 0.1 & 16.45 & 1.02 & 421.66 & 368.69 & 541.10 & 12.56 \\
\hline $\begin{array}{c}\text { Case } \\
2 \\
\end{array}$ & 5.537 & 0.13 & 16.37 & 0.85 & 365.45 & 320.73 & 437.80 & 12.24 \\
\hline $\begin{array}{c}\text { Case } \\
3\end{array}$ & 5.537 & 0.15 & 16.36 & 0.78 & 323.66 & 305.42 & 396.48 & 5.64 \\
\hline $\begin{array}{c}\text { Case } \\
4\end{array}$ & 5.563 & 0.19 & 16.41 & 0.67 & 286.31 & 247.83 & 333.20 & 13.44 \\
\hline $\begin{array}{c}\text { Case } \\
5\end{array}$ & 5.578 & 0.22 & 16.41 & 0.60 & 254.17 & 220.64 & 293.91 & 13.19 \\
\hline $\begin{array}{c}\text { Case } \\
6\end{array}$ & 5.580 & 0.25 & 16.52 & 0.55 & 243.77 & 210.55 & 266.60 & 13.63 \\
\hline $\begin{array}{c}\text { Case } \\
7\end{array}$ & 5.593 & 0.33 & 16.53 & 0.46 & 218.88 & 187.69 & 218.36 & 14.25 \\
\hline $\begin{array}{c}\text { Case } \\
8\end{array}$ & 5.590 & 0.35 & 16.48 & 0.44 & 214.51 & 186.4 & 207.79 & 13.10 \\
\hline $\begin{array}{c}\text { Case } \\
9\end{array}$ & 5.6 & 0.39 & 16.48 & 0.41 & 202.24 & 173.96 & 192.25 & 13.98 \\
\hline $\begin{array}{c}\text { Case } \\
10 \\
\end{array}$ & 5.636 & 0.46 & 16.51 & 0.37 & 197.45 & 184.64 & 171.92 & 6.49 \\
\hline $\begin{array}{c}\text { Case } \\
11\end{array}$ & 5.691 & 0.57 & 16.55 & 0.32 & 180.37 & 173.26 & 147.13 & 3.94 \\
\hline $\begin{array}{c}\text { Case } \\
12 \\
\end{array}$ & 5.830 & 0.7 & 16.42 & 0.29 & 160.58 & 137.89 & 132.40 & 14.13 \\
\hline $\begin{array}{c}\text { Case } \\
13\end{array}$ & 6.137 & 0.85 & 16.53 & 0.26 & 148.44 & 127.92 & 118.30 & 13.82 \\
\hline
\end{tabular}




\begin{tabular}{|c|c|c|c|c|c|c|c|c|}
\hline $\begin{array}{c}\text { Case } \\
14\end{array}$ & 6.186 & 0.87 & 16.57 & 0.26 & 132.24 & 120.64 & 118.36 & 8.77 \\
\hline
\end{tabular}

Note, $\rho_{0}=1.29 \mathrm{~kg} \mathrm{~m}^{-3}, c_{p}=1.003 \mathrm{~kJ} \mathrm{~kg}^{-1} \mathrm{~K}^{-1}, H_{d}=0.38 m$.

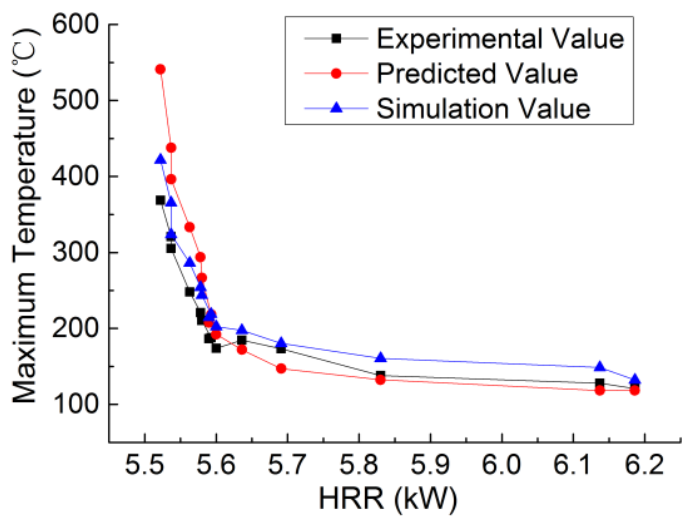

Fig. 4. Comparison of $\mathrm{T}_{\max }$ obtained by three different methods

Changing trends of the maximum fire smoke temperature obtained by the three different methods were in good accordance. The value of the Kurioka model was close to the simulation value and experimental results for the cases in which $\frac{Q^{* 2 / 3}}{F^{1 / 3}}$ was small. The simulation value of the maximum fire smoke temperature obtained by numerical simulation was generally larger than the experimental value. The conclusion agreed with the existing conclusion, and the maximum fire smoke temperature obtained by numerical simulation for cases in which the combustion model was used in the numerical simulation was higher than the temperature obtained experimentally ${ }^{[17]}$. Meanwhile, the simulation value of each case was close to the experimental value of the responding case, with deviation within $15 \%$, which indicated that the using the numerical simulation to predict the maximum fire smoke temperature beneath the tunnel ceiling was authentic.

\section{The modification of the Kurioka model}

According to previous conclusions, the Kurioka model indicated that the maximum fire smoke temperature remained constant for cases in which $\frac{Q^{* 2 / 3}}{\mathrm{Fr}^{1 / 3}}$ was more than 1.35 , which did not agree with the result of large-scale experiments. On the basis that the validity of the numerical simulation had been verified, numerical simulation was used to investigate the variation of the maximum fire smoke temperature beneath the tunnel ceiling for large HRR.

\subsection{Simulation cases}

The influences of large HRR on the maximum fire smoke temperature beneath the tunnel ceiling were simulated, as listed in Table 2, to modify the Kurioka model. The geometric model was identical to the model employed in the previous numerical simulation. The fire source in the numerical simulation was also methane. The combustion was also considered as a stoichiometric reaction of methane and air, defined as Eq. (2). 
$Q^{*}$ and $F r$, shown in Table 2, were also determined by Eq. (1). Parameters used to obtain $Q^{*}$ and $\mathrm{Fr}$, the general form of the governing equation and boundary conditions were the same as previous conditions. Numerical simulation also used SIMPLE method. The simulation solver was CFX 15.0.

\subsection{Result and analysis}

\subsubsection{Relationship between simulation result and the Kurioka model}

The simulation results are summarized in Table 2. For $\frac{Q^{* 2 / 3}}{F r}$ continuously increasing, the maximum fire smoke temperature beneath the tunnel ceiling also increased, which was much higher than the temperature obtained by the Kurioka model, as shown in Fig. 5.

Table 2. Simulation cases and results with great HRR

\begin{tabular}{|c|c|c|c|c|c|c|c|}
\hline No. & $\begin{array}{c}\mathrm{HRR} \\
(\mathrm{kW})\end{array}$ & $\begin{array}{c}\mathrm{T} 0 \\
\left.{ }^{\circ} \mathrm{C}\right)\end{array}$ & $\begin{array}{c}\text { Inlet Velocity of } \\
\text { Methane }\left(\mathrm{m} \cdot \mathrm{s}^{-1}\right)\end{array}$ & $\begin{array}{c}\mathrm{u} \\
\left(\mathrm{m} \cdot \mathrm{s}^{-1}\right)\end{array}$ & $\begin{array}{c}Q^{* 2 / 3} \\
F^{1 / 3}\end{array}$ & $\begin{array}{c}\text { Simulation } \\
\text { Value }\end{array}$ & $\begin{array}{c}\text { Predicted } \\
\text { Value }\end{array}$ \\
\hline $\begin{array}{c}\text { Case } \\
\text { S-1 }\end{array}$ & 10 & 16 & 0.02228 & 0.1 & 1.38 & 721.26 & 750.06 \\
\hline $\begin{array}{c}\text { Case } \\
\text { S-2 }\end{array}$ & 11 & 16 & 0.02451 & 0.1 & 1.47 & 795.35 & 750.06 \\
\hline $\begin{array}{c}\text { Case } \\
\text { S-3 }\end{array}$ & 12 & 16 & 0.02674 & 0.1 & 1.56 & 830.44 & 750.06 \\
\hline $\begin{array}{c}\text { Case } \\
\text { S-4 }\end{array}$ & 13 & 16 & 0.02897 & 0.1 & 1.65 & 864.86 & 750.06 \\
\hline $\begin{array}{c}\text { Case } \\
\text { S-5 }\end{array}$ & 14 & 16 & 0.03120 & 0.1 & 1.73 & 898.51 & 750.06 \\
\hline $\begin{array}{c}\text { Case } \\
\text { S-6 }\end{array}$ & 15 & 16 & 0.03343 & 0.1 & 1.81 & 971.45 & 750.06 \\
\hline $\begin{array}{c}\text { Case } \\
\text { S-7 }\end{array}$ & 16 & 16 & 0.03565 & 0.1 & 1.89 & 983.66 & 750.06 \\
\hline $\begin{array}{c}\text { Case } \\
\text { S- }\end{array}$ & 17 & 16 & 0.03788 & 0.1 & 1.97 & 1042.86 & 750.06 \\
\hline $\begin{array}{c}\text { Case } \\
\text { S-9 }\end{array}$ & 18 & 16 & 0.04011 & 0.1 & 2.05 & 1050.51 & 750.06 \\
\hline $\begin{array}{c}\text { Case } \\
\text { S-10 }\end{array}$ & 19 & 16 & 0.04234 & 0.1 & 2.12 & 1053.12 & 750.06 \\
\hline $\begin{array}{c}\text { Case } \\
\text { S-11 }\end{array}$ & 20 & 16 & 0.04457 & 0.1 & 2.19 & 1056.43 & 750.06 \\
\hline $\begin{array}{c}\text { Case } \\
\text { S-12 }\end{array}$ & 21 & 16 & 0.04680 & 0.1 & 2.27 & 1061.89 & 750.06 \\
\hline $\begin{array}{c}\text { Case } \\
\text { S-13 }\end{array}$ & 22 & 16 & 0.04903 & 0.1 & 2.34 & 1067.66 & 750.06 \\
\hline $\begin{array}{c}\text { Case } \\
\text { S-14 }\end{array}$ & 23 & 16 & 0.05125 & 0.1 & 2.41 & 1074.97 & 750.06 \\
\hline $\begin{array}{c}\text { Case } \\
\text { S-15 }\end{array}$ & 24 & 16 & 0.05348 & 0.1 & 2.48 & 1076.88 & 750.06 \\
\hline $\begin{array}{c}\text { Case } \\
\text { S-16 }\end{array}$ & 25 & 16 & 0.05571 & 0.1 & 2.55 & 1079.49 & 750.06 \\
\hline $\begin{array}{c}\text { Case } \\
\text { S-17 }\end{array}$ & 26 & 16 & 0.05794 & 0.1 & 2.61 & 1084.83 & 750.06 \\
\hline $\begin{array}{c}\text { Case } \\
\text { S-18 }\end{array}$ & 27 & 16 & 0.06017 & 0.1 & 2.68 & 1093.19 & 750.06 \\
\hline $\begin{array}{c}\text { Case } \\
\text { S-19 }\end{array}$ & 28 & 16 & 0.06240 & 0.1 & 2.75 & 1095.96 & 750.06 \\
\hline $\begin{array}{c}\text { Case } \\
\text { S-20 }\end{array}$ & 29 & 16 & 0.06462 & 0.1 & 2.81 & 1108.92 & 750.06 \\
\hline
\end{tabular}




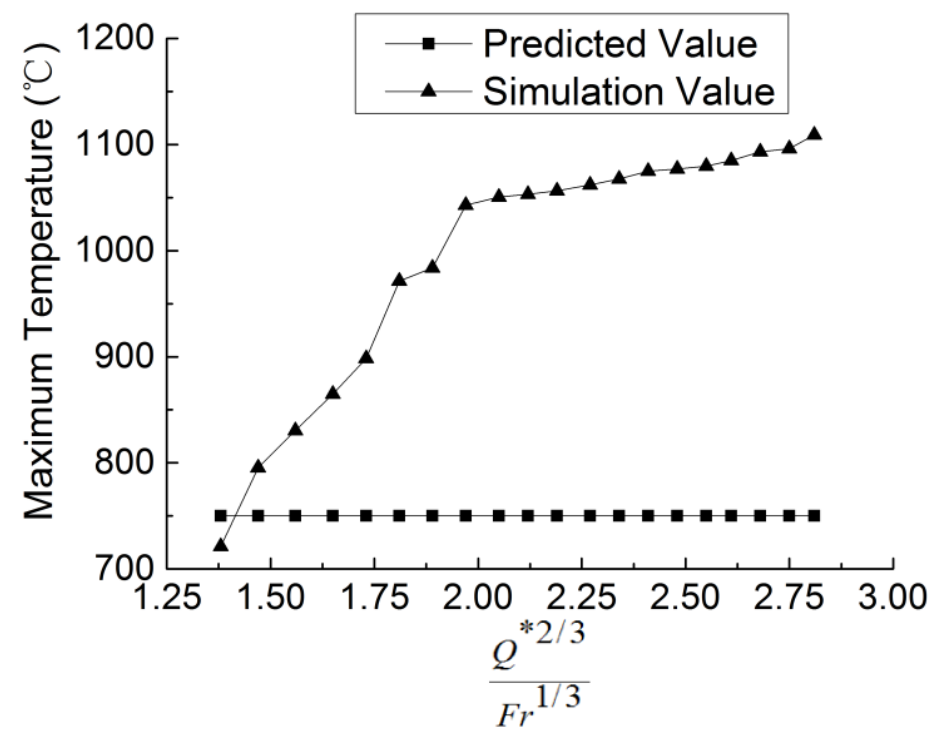

Fig. 5. Comparison of $\mathrm{T}_{\max }$ obtained by two different methods

\subsubsection{Modification of the Kurioka model based on the simulation results}

According to the simulation results, the Kurioka model was modified specifically for the cases in which $\frac{Q^{* 2 / 3}}{\mathrm{Fr}^{1 / 3}}$ was more than 1.35. Correction factors, $\varepsilon$ and $\gamma$, were required, as shown in Eq. (4)

$$
\frac{\Delta T_{\max }}{T_{0}}=\gamma\left(\frac{Q^{* 2 / 3}}{F r^{1 / 3}}\right)^{\varepsilon}
$$

Use log function on both sides, as shown in Eq. (5)

$$
\ln \frac{\Delta T_{\max }}{T_{0}}=\ln \gamma+\varepsilon \ln \left(\frac{Q^{* 2 / 3}}{F r^{1 / 3}}\right)
$$

Set $Y=\ln \frac{\Delta T_{\max }}{T_{0}}, X=\ln \left(\frac{Q^{* 2 / 3}}{F r^{1 / 3}}\right)$, as shown in Eq. (6)

$$
Y=\ln \gamma+\varepsilon X
$$

Based on the simulation results shown in Table 8 , the modified empirical formulas were obtained by data fitting, as shown in Fig. (6), Fig. (7), Eq. (7) and Eq. (8). 


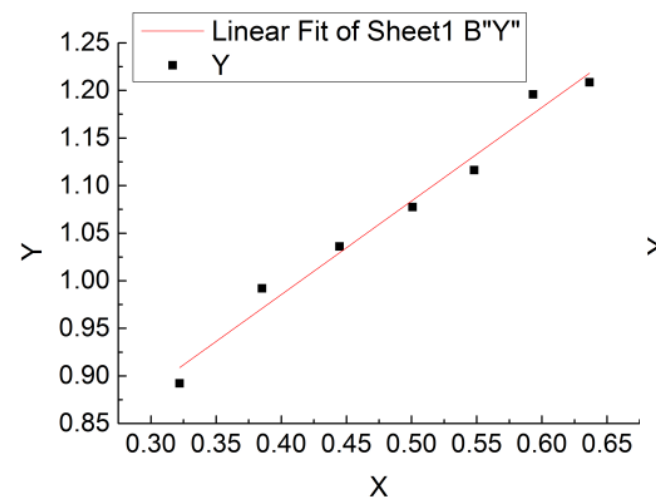

Fig. 6. Fitting curve, $1.35 \leq\left(\frac{Q^{* 2 / 3}}{F r^{1 / 3}}\right) \leq 1.89$

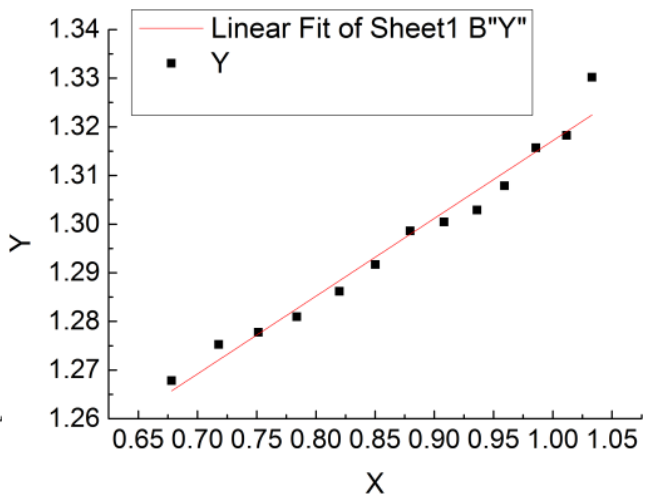

Fig. 7. Fitting curve, $\left(\frac{Q^{* 2 / 3}}{F^{1 / 3}}\right)>1.89$

$$
\begin{gathered}
Y=0.9894 X+0.5884, R^{2}=0.98,1.35 \leq\left(\frac{Q^{* 2 / 3}}{F r^{1 / 3}}\right) \leq 1.89 \\
Y=0.1596 X+1.575, R^{2}=0.97,\left(\frac{Q^{* 2 / 3}}{F r^{1 / 3}}\right)>1.89
\end{gathered}
$$

Put Eq. (7) and Eq. (8) into the original type, as shown in Eq. (9) and Eq. (10)

$$
\begin{gathered}
\frac{\Delta T_{\max }}{T_{0}}=\gamma\left(\frac{Q^{* 2 / 3}}{F r^{1 / 3}}\right)^{\varepsilon}, \gamma=1.801, \varepsilon=0.9894,1.35 \leq\left(\frac{Q^{* 2 / 3}}{F r^{1 / 3}}\right) \leq 1.89 \\
\frac{\Delta T_{\max }}{T_{0}}=\gamma\left(\frac{Q^{* 2 / 3}}{F r^{1 / 3}}\right)^{\varepsilon}, \gamma=3.182, \varepsilon=0.1596,\left(\frac{Q^{* 2 / 3}}{F r^{1 / 3}}\right)>1.89
\end{gathered}
$$

\subsubsection{Verification of the modified Kurioka model}

To verify the validity of the modified Kurioka model, the published data ${ }^{[10]}$ was employed to compare with the predicted maximum fire smoke temperature obtained by Eq. (9) and Eq. (10), as shown in Table 3.

The comparison indicates that there was a difference in predicting the maximum fire smoke temperature beneath the tunnel of the two methods. However, the maximum deviation is within $15 \%$, which means the modified Kurioka model is certain credibility.

Table 3. Comparison of $\mathrm{T}_{\max }$ obtained by experiments and the modified Kurioka model

\begin{tabular}{|c|c|c|c|c|c|}
\hline \multirow{2}{*}{ No. } & \multirow{2}{*}{ HRR(MW) } & \multirow{2}{*}{$Q^{* 2 / 3}$} & \multicolumn{2}{|c|}{$\mathrm{T}_{\max }\left({ }^{\circ} \mathrm{C}\right)$} & \multirow{2}{*}{ Deviation/\% } \\
\cline { 5 - 6 } & & $F r$ & Experimental Value & Predicted Value & \\
\hline 1 & 202 & 12.32 & 1325 & 1471.53 & -7.80 \\
\hline 2 & 157 & 10.41 & 1365 & 1433.13 & -11.79 \\
\hline 3 & 119 & 8.66 & 1282 & 1392.07 & -8.67 \\
\hline 4 & 66 & 5.84 & 1281 & 1308.66 & -0.28 \\
\hline
\end{tabular}

Note: Ambient temperature is assumed to be $20^{\circ} \mathrm{C}$ to calculate the maximum fire smoke temperature. 


\section{Conclusions}

The maximum fire smoke temperature beneath the tunnel ceiling was studied experimentally and numerically for small HRR to verify the validity of the numerical simulation. The numerical simulation was subsequently used to solve the problem that the large difference of the maximum fire smoke temperature for a large HRR fire exists between the results obtained from full-scale experiments and the Kurioka model. Fire scenarios with large HRR were then simulated by CFX 15.0. According to simulation results, the Kurioka model was modified. The present studies show the following:

(1) Differences exist in obtaining maximum fire smoke temperature through experiments and numerical simulation, due to the combustion model used in simulation. The highest difference of the two methods is within $15 \%$, which proves the validity of the numerical simulation.

(2) Changing trends of the maximum fire smoke temperature obtained by three different methods, experiments, numerical simulations and the Kurioka model, are in good agreement. The value of the Kurioka model is close to the value of the simulation and experiments for the cases in which $\frac{Q^{* 2 / 3}}{F r}$ is small.

(3) In terms of the numerical simulation results, the Kurioka model was partly modified to accurately predict the maximum fire smoke temperature, as shown in Eq. (9) and Eq. (10).

(4) The accuracy of the modified Kurioka model was proved by the data in published research works. The analysis showed that the modified Kurioka model can predict maximum fire smoke temperature with highest deviation less than $15 \%$. The modification of Kurioka model is believable.

Since the analytical model at this research stage is simple, it is important to recall its limitations in order to avoid improper use. The model is only valid for rectangular tunnels, as described in Fig.1. In the future, based on the present model, more comprehensive model would be studied and developed by considering different tunnel shapes.

\section{References}

1. A. Haack, Tunnel. Tunn. Undergr. Sp Tech. 17, 117-127(2002)

2. E. Migoya, J. Garcia, A. Crespo, C. Gago, A. Rubio, Tunn. Undergr. Sp Tech. 26, 211-222 (2011)

3. L. Barbato, F. Cascetta, M. Musto, G. Rotondo, Tunn. Undergr. Sp Tech. 43, 253-265 (2014)

4. F. Tang, F.Z. Mei, Q. Wang, Z. He, C.G. Fan, C.F. Tao, Tunn. Undergr. Sp Tech. 68, 231-237 (2017)

5. Y. Z. Li, H. Ingason, Fire Safety J. 48, 38-48 (2012)

6. Y. Z. Li, B. Lei, H. Ingason, Fire Safety J. 46, 204-210 (2011)

7. L.H. Hu, R. Huo, W. Peng, W.K. Chow, R.X. Yang, Tunn. Undergr. Sp Tech. 21, 650-655 (2006)

8. H. Kurioka, Y. Okab, H. Satoha, O. Sugawa, Fire Safety J. 38, 319-340 (2003)

9. L. Yi, J.L. Niu, Z.S. Xu, D.X. Wu, Tunn. Undergr. Sp Tech. 35, 135-141 (2013)

10. A. Lonnermark, H. Ingason, Fire Safety J. 40, 506-527 (2005)

11. H. Ingason, Y. Z. Li, A. Lönnermark, Fire Safety J. 71, 134-139 (2015) 
12. J. G. Quintiere, Fire Safety J. 15, 3-29 (1989)

13. J. Wang, L. Zhao, Chin J Undergr Space Eng. 12, 1524-1531 (2016)

14. H. Ingason, Z. Ying, Fire Safety J. 45, 371-384 (2010)

15. P. L. Huang, Experimental Study on Gas Control in Tunnel Fire (BUCEA, China, 2010)

16. W. C. Fan, J. H. Sun, The fire risk assessment methodology (Science Press, China, 2004)

17. H. Yang, Numerical study on air and gas flow characteristics in subway space (BJTU, China, 2010) 